American Journal of Applied Sciences 7 (11): 1504-1508, 2010

ISSN 1546-9239

(C) 2010 Science Publications

\title{
Power System Stability Enhancement Using Unified Power Flow Controller
}

\author{
Prechanon Kumkratug \\ Department of Electrical Engineering, Faculty of Engineering at Si Racha, \\ Kasetsart University, 199 M.6, Tungsukhla, Si Racha, Chonburi, 20230, Thailand
}

\begin{abstract}
Problem statement: The enhancement of transient stability of the power system is one of the most challenging research areas in power engineer. Approach: This study presents the method to enhance transient stability of power system by Unified Power Flow Controller (UPFC). The mathematical model of power system equipped with a UPFC is systematically derived. The parameters of UPFC are modeled into power flow equation and thus it is used to determine control strategy. The swing curves of the three phase faulted power system without and with a UPFC are tested and compared in various cases. Results: The swing curve of system without a UPFC gets increases monotonically and thus the system can be considered as unstable whereas the swing curves of system with a UPFC can return to stable equilibrium point. Conclusion: From the simulation results, the UPFC can enhance transient stability of power system.
\end{abstract}

Key words: Power system, Unified Power Flow Controller (UPFC), transient stability, High Voltage Direct Current (HVDC), Flexible AC Transmission System (FACTS), injected current, thyristor controlled phase shifter, series transformer, voltage source, leakage reactance, equivalent circuit

\section{INTRODUCTION}

Modern power system network is getting much more complicated and heavily loaded than ever before. The consequence of such is the risk of stability problem. Transient stability is one of the important aspects in power system (Zarate-Minano at al., 2010; Pizano-Matinez at al., 2009; Augusto at al., 2008). There are many advanced devices have been proposed during the last three decades to improve stability of power system such as High Voltage Direct Current (HVDC) system and Flexible AC Transmission System (FACTS) devices (Ahmad and Al-Husban, 2009; Moghadasi et al., 2008; Kumkratug, 2010).

The Unified Power Flow Controller (UPFC) is a member of FACTS devices. It consists of two solid state converters. They are coupled through a common DC link (Hannan et al., 2009; Jiang et al., 2008). To verify the capability of UPFC on transient stability enhancement, its suitable mathematical model and control strategy are needed to be presented.

This study presents the mathematical model of power system equipped with a UPFC. The presented mathematical model is applied to design control strategy of a UPFC. The simulation results are tested on a Single Machine Infinite bus system.

\section{MATERIALS AND METHODS}

Mathematical model: Consider the schematic diagram of a UPFC as shown in Fig. 1a. The equivalent circuit of Fig. 1a is shown in Fig. 1b where the converters are replaced by synchronous voltage sources in series with the associate transformer leakage reactance. In the equivalent circuit, subscripts ' $s$ ' and 'sh' are used to represent the quantities of the series and shunt converters, respectively. The shunt converter voltage and the associated transformer leakage reactance can be replaced by a shunt current source as shown in Fig. 1c. The value of the shunt current $I_{s h}$ is given by:

$\mathbf{I}_{\mathrm{sh}}=\frac{\left(\mathbf{V}_{\mathrm{sh}}-\mathbf{V}_{\mathrm{m}}\right)}{\mathrm{j} X_{\mathrm{sh}}}$

Here $V_{m}$ is the complex voltage of bus $m$. The injected shunt current can be controlled by adjusting the shunt converter voltage $\mathrm{V}_{\mathrm{sh}}$.

Consider a simple power system transferring power from a generating station to an infinite bus through a transformer and a transmission line having two parts as shown in Fig. 2a. A UPFC is placed in the transmission line at point $\mathrm{m}$ (between the two lines to enhance the dynamic behaviour of the system. The reactance diagram of the system is shown in Fig. $2 b$. E' and $V_{b}$ 
are the machine voltage and infinite bus voltage, respectively. The $X_{1}$ represents the equivalent reactance between the machine internal bus to bus $m$ and $X_{2}$ represents the equivalent reactance between bus $m$ to infinite bus.

The complex power supplied by the series converter can be written as:

$$
\begin{aligned}
\mathbf{S}_{\mathrm{s}}^{\mathrm{u}} & =\left[\mathrm{P}_{\mathrm{s}}^{\mathrm{u}}+\mathrm{j} \mathrm{Q}_{\mathrm{s}}^{\mathrm{u}}\right]=\mathbf{V}_{\mathrm{s}}\left(-\mathbf{I}_{\mathrm{u}}\right)^{*} \\
& =\mathbf{V}_{\mathrm{s}}\left[\frac{-\mathbf{V}_{\mathrm{m}}^{\mathrm{u}}+\mathbf{V}_{\mathrm{s}}+\mathrm{V}_{\mathrm{b}}}{\mathrm{j} \mathbf{X}_{2}}\right]^{*}
\end{aligned}
$$

Here $I_{u}$ is the line current.

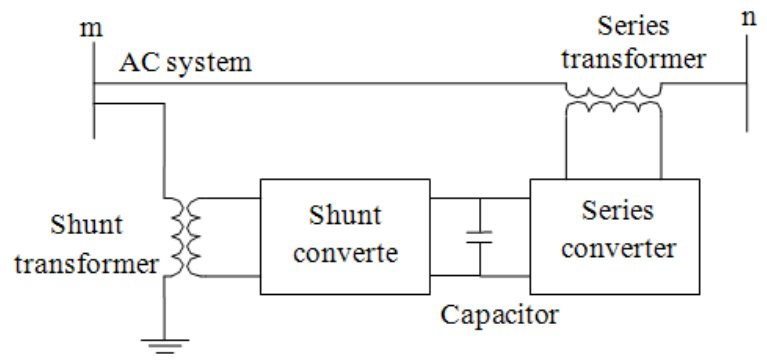

(a)

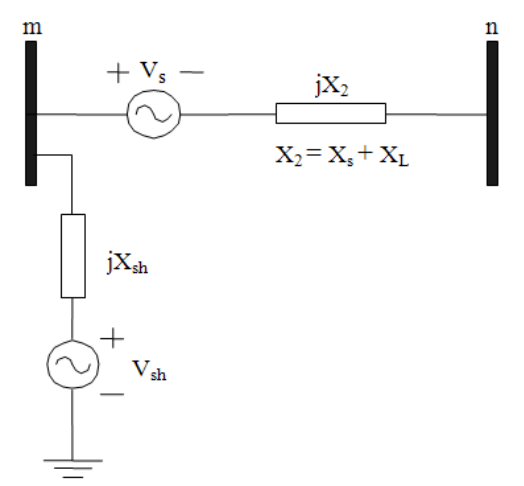

(b)

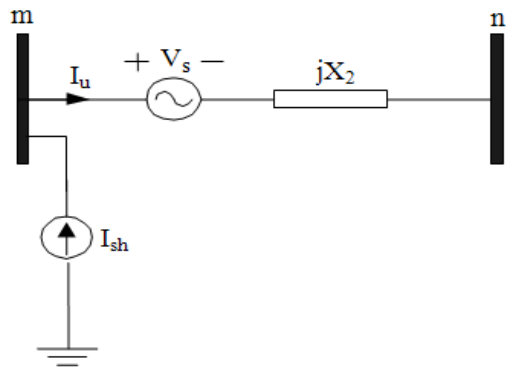

(c)

Fig. 1: Representation of a UPFC: (a) schematic diagram; (b) equivalent circuit; (c) current injection model
The active $\left(\mathrm{P}_{\mathrm{s}}^{\mathrm{u}}\right)$ and reactive $\left(\mathrm{Q}_{\mathrm{s}}^{\mathrm{u}}\right)$ powers supplied by the series converter are given by:

$$
\begin{aligned}
\mathrm{P}_{\mathrm{s}}^{\mathrm{u}} & =\operatorname{Re}\left[\mathbf{S}_{\mathrm{s}}^{\mathrm{u}}\right] \\
& =-\mathrm{bV}_{\mathrm{s}} \mathrm{V}_{\mathrm{b}} \sin \left(\theta_{\mathrm{s}}-\theta_{\mathrm{m}}^{\mathrm{u}}\right)+\mathrm{bV}_{\mathrm{s}} \mathrm{V}_{\mathrm{m}}^{\mathrm{u}} \sin \left(\theta_{\mathrm{s}}-\theta_{\mathrm{m}}^{\mathrm{u}}\right) \\
\mathrm{Q}_{\mathrm{s}}^{\mathrm{u}} & =\operatorname{Im}\left[\mathbf{S}_{\mathrm{s}}^{\mathrm{u}}\right] \\
& =-b \mathrm{~V}_{\mathrm{s}} \mathrm{V}_{\mathrm{m}}^{\mathrm{u}} \cos \left(\theta_{\mathrm{s}}-\theta_{\mathrm{m}}^{\mathrm{u}}\right)+\mathrm{bV}_{\mathrm{s}}^{2}+\mathrm{bV}_{\mathrm{s}} \mathrm{V}_{\mathrm{b}} \cos \left(\theta_{\mathrm{s}}\right)
\end{aligned}
$$

Here $\mathrm{V}_{\mathrm{s}}$ and $\theta_{\mathrm{s}}$ are the series voltage magnitude and angle, respectively and $\mathrm{b}=1 / \mathrm{X}_{2}$

The complex power dawn by the shunt converter can be written as:

$\mathbf{S}_{\mathrm{sh}}^{\mathrm{u}}=\left[\mathrm{P}_{\mathrm{sh}}^{\mathrm{u}}+\mathrm{jQ} \mathrm{Q}_{\mathrm{sh}}^{\mathrm{u}}\right]=\mathbf{V}_{\mathrm{m}}^{\mathrm{u}}\left(-\mathbf{I}_{\mathrm{sh}}\right)^{*}$

The shunt injected current $\mathrm{I}_{\mathrm{sh}}$ can be resolved into two components: one is in phase $\left(\mathrm{I}_{\mathrm{p}}\right)$ with $\mathrm{V}_{\mathrm{m}}$ and the other is in quadrature $\left(\mathrm{I}_{\mathrm{q}}\right)$ with $\mathrm{V}_{\mathrm{m}}$ as can be seen in Fig. 3. Thus $I_{\text {sh }}$ can be expressed as:

$\mathbf{I}_{\mathrm{sh}}=\left(\mathrm{I}_{\mathrm{p}}-\mathrm{j} \mathrm{I}_{\mathrm{q}}\right) \mathrm{e}^{\mathrm{j} \theta_{\mathrm{m}}^{\mathrm{u}}}$

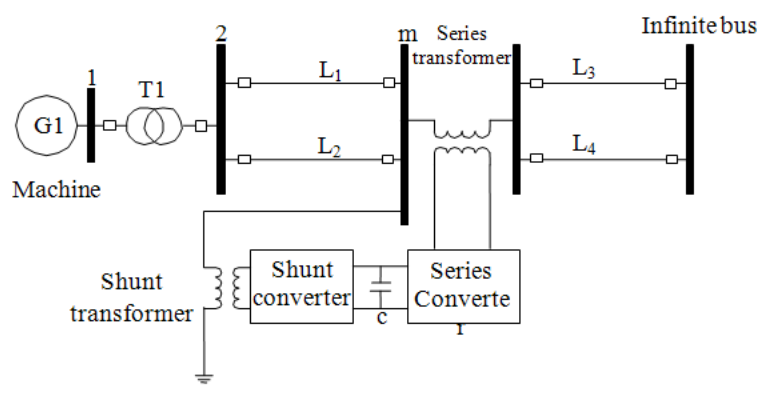

(a)

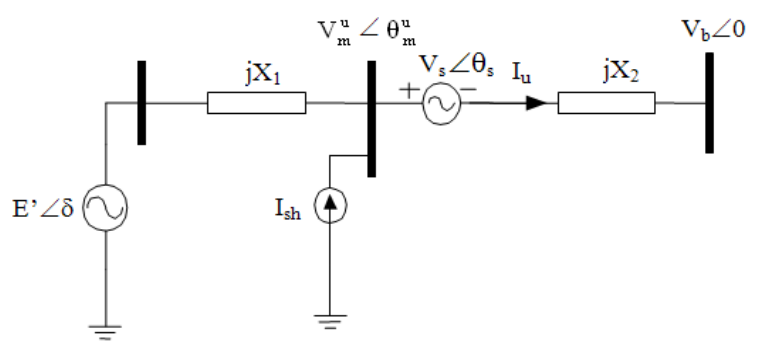

(b)

Fig. 2: A simple single machine infinite bus system with a UPFC; (a) single line diagram; (b) Equivalent circuit of UPFC in a SMIB 


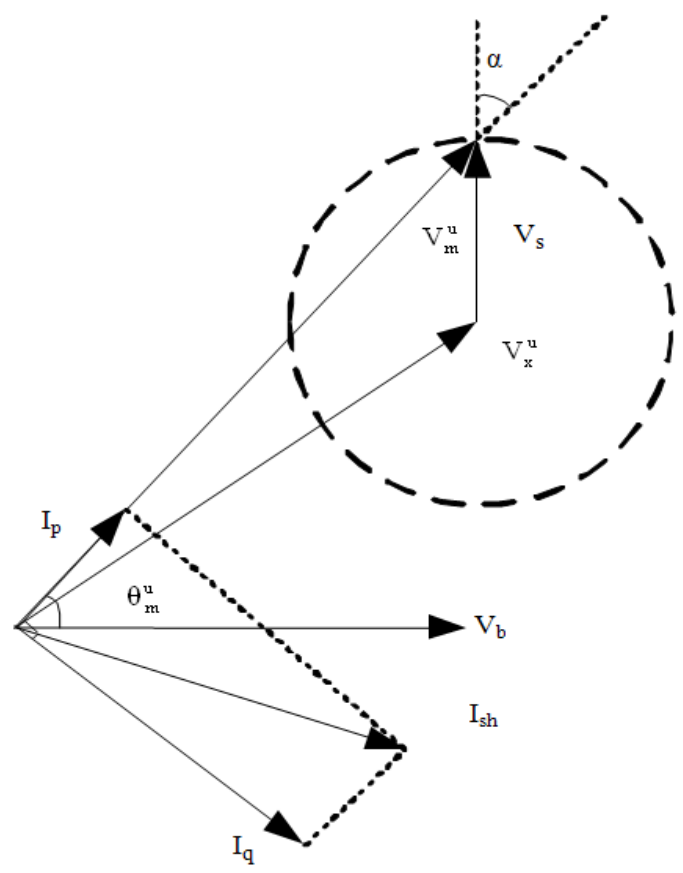

Fig. 3: Vector diagram of UPFC

The active $P_{s h}^{u}$ and reactive $Q_{s h}^{u}$ power drawn by the shunt transformer can be written as:

$$
\mathrm{P}_{\mathrm{sh}}^{\mathrm{u}}=\operatorname{Re}\left[\mathbf{S}_{\mathrm{sh}}^{\mathrm{u}}\right]=\operatorname{Re}\left[\mathbf{V}_{\mathrm{m}}^{\mathrm{u}}\left(-\mathbf{I}_{\mathrm{sh}}\right)^{*}\right]=-\mathrm{V}_{\mathrm{m}}^{\mathrm{u}} \mathrm{I}_{\mathrm{p}}
$$

$\mathrm{Q}_{\mathrm{sh}}^{\mathrm{u}}=\operatorname{Im}\left[\mathbf{S}_{\mathrm{sh}}^{\mathrm{u}}\right]=\operatorname{Im}\left[\mathbf{V}_{\mathrm{m}}^{\mathrm{u}}\left(-\mathbf{I}_{\mathrm{sh}}\right)^{*}\right]=-\mathrm{V}_{\mathrm{m}}^{\mathrm{u}} \mathrm{I}_{\mathrm{q}}$

The active power drawn by the shunt converter is equal to the active power supplied by the series converter:

$\mathrm{P}_{\mathrm{sh}}^{\mathrm{u}}=\mathrm{P}_{\mathrm{s}}^{\mathrm{u}}$

Using Eq. 3, 7 and 9, the in phase component of shunt injected current $\mathrm{I}_{\mathrm{p}}$ can be written as:

$I_{p}=\frac{b V_{s}}{V_{m}^{u}} \sin \left(\theta_{s}\right)-b V_{s} \sin \left(\theta_{s}-\theta_{m}^{u}\right)$

Consider $\mathbf{V}_{\mathrm{s}} / \mathbf{V}_{\mathrm{m}}^{\mathrm{u}}=\mathrm{ae}^{\mathrm{j} \alpha}$. The control ranges of a and $\alpha$ are $0 \leq \mathrm{a} \leq \mathrm{a}_{\max }$ and $-\pi \leq \alpha \leq \pi$, respectively. Thus Eq. 10 can be written as:

$I_{p}=a b V_{b} \sin \left(\theta_{m}^{u}+\alpha\right)-a b V_{m}^{u} \sin (\alpha)$

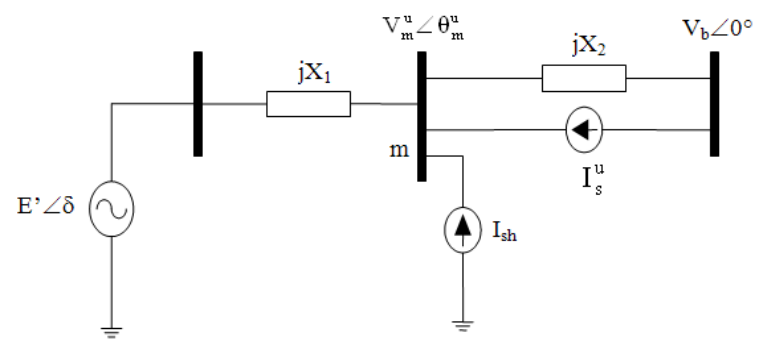

(a)

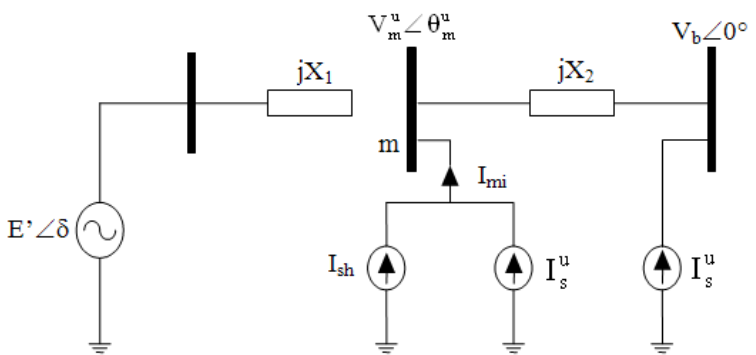

(b)

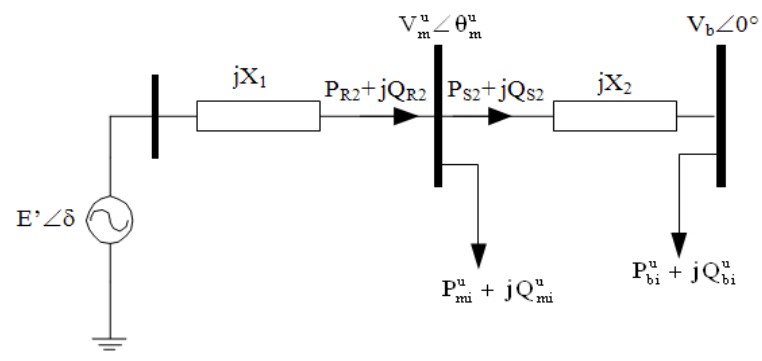

(c)

Fig. 4: Successive representation of series voltage source of the UPFC: (a) voltage source converted to a current source; (b) current source represented by two current sources; (c) fictitious load model

The series converter voltage Vs of Fig. $2 b$ can be transformed into a current source $I_{s}^{u}$ as shown in Fig. 4a. The value of $\mathrm{I}_{\mathrm{s}}^{\mathrm{u}}$ as shown in Fig. 4a is given by:

$\mathrm{I}_{\mathrm{s}}^{\mathrm{u}}=\frac{\mathbf{V}_{\mathrm{s}}}{\mathrm{jX}}=-\mathrm{jabe}^{\mathrm{j} \alpha} \mathbf{V}_{\mathrm{m}}^{\mathrm{u}}$

The current source connected between bus $m$ and $n$ can be replaced by two shunt current source as shown in Fig. $4 b$. The net injected current $I_{\mathrm{mi}}$ at bus $\mathrm{m}$ can be written as:

$$
\begin{aligned}
I_{m i} & =\left[I_{s h}+I_{s}^{u}\right]=\left[a b V_{b} \sin \left(\theta_{m}^{u}+\alpha\right)\right. \\
& \left.-a b V_{m}^{u} \sin (\alpha)-j I_{q}\right] e^{j \theta_{m}^{u}}-j a b e^{j \alpha} V_{m}^{u}
\end{aligned}
$$


The fictitious complex load at bus $m$ as shown in Fig. 4c is given by:

$\mathrm{S}_{\mathrm{mi}}^{\mathrm{u}}=\left(\mathrm{P}_{\mathrm{mi}}^{\mathrm{u}}+\mathrm{jQ} \mathrm{mi}_{\mathrm{mi}}^{\mathrm{u}}\right)=\mathbf{V}_{\mathrm{m}}^{\mathrm{u}}\left(-\mathbf{I}_{\mathrm{mi}}\right)^{*}$

The fictitious active $\mathrm{P}_{\mathrm{mi}}^{\mathrm{u}}$ and reactive load $\mathrm{Q}_{\mathrm{mi}}^{\mathrm{u}}$ at bus $m$ are given by:

$$
\begin{aligned}
& \mathrm{P}_{\mathrm{mi}}^{\mathrm{u}}=\operatorname{Re}\left[\mathbf{S}_{\mathrm{mi}}^{\mathrm{u}}\right]=-\mathrm{abV} \mathrm{V}_{\mathrm{m}}^{\mathrm{u}} \mathrm{V}_{\mathrm{b}} \sin \left(\theta_{\mathrm{m}}^{\mathrm{u}}+\alpha\right) \\
& \mathrm{Q}_{\mathrm{mi}}^{\mathrm{u}}=\operatorname{Im}\left[\mathbf{S}_{\mathrm{mi}}^{\mathrm{u}}\right]=-\mathrm{I}_{\mathrm{q}} \mathrm{V}_{\mathrm{m}}^{\mathrm{u}}-\mathrm{ab}\left(\mathrm{V}_{\mathrm{m}}^{\mathrm{u}}\right)^{2} \cos (\alpha)
\end{aligned}
$$

The fictitious complex load at infinite bus $b$ is given by:

$\mathbf{S}_{\mathrm{bi}}^{\mathrm{u}}=\left(\mathrm{P}_{\mathrm{bi}}^{\mathrm{u}}+\mathrm{j} \mathrm{Q}_{\mathrm{bi}}^{\mathrm{u}}\right)=\mathrm{V}_{\mathrm{b}}\left(-\mathbf{I}_{\mathrm{s}}^{\mathrm{u}}\right)$

The fictitious active $\mathrm{P}_{\mathrm{ni}}^{\mathrm{u}}$ and reactive $\mathrm{Q}_{\mathrm{ni}}^{\mathrm{u}}$ load at infinite bus b are given by:

$\mathrm{P}_{\mathrm{bi}}^{\mathrm{u}}=\operatorname{Re}\left[\mathbf{S}_{\mathrm{bi}}^{\mathrm{u}}\right]=-\mathrm{abV} \mathrm{V}_{\mathrm{m}}^{\mathrm{u}} \mathrm{V}_{\mathrm{b}} \sin \left(\theta_{\mathrm{m}}^{\mathrm{u}}+\alpha\right)$

$\mathrm{Q}_{\mathrm{bi}}^{\mathrm{u}}=\operatorname{Re}\left[\mathbf{S}_{\mathrm{bi}}^{\mathrm{u}}\right]=\mathrm{abV}_{\mathrm{m}}^{\mathrm{u}} \mathrm{V}_{\mathrm{b}} \cos \left(\theta_{\mathrm{m}}^{\mathrm{u}}+\alpha\right)$

The active power balance equations at bus $\mathrm{m}$ of Fig. 4c is:

$$
\begin{aligned}
\mathrm{P}_{\mathrm{R} 1} & =\mathrm{P}_{\mathrm{mi}}^{\mathrm{u}}+\mathrm{P}_{\mathrm{S} 2} \frac{\mathrm{E}^{\prime} \mathrm{V}_{\mathrm{m}}^{\mathrm{u}}}{\mathrm{X}_{1}} \sin \left(\delta-\theta_{\mathrm{m}}^{\mathrm{u}}\right) \\
& =-a b V_{\mathrm{m}}^{\mathrm{u}} \mathrm{V}_{\mathrm{b}} \sin \left(\theta_{\mathrm{m}}^{\mathrm{u}}+\alpha\right)+\frac{\mathrm{V}_{\mathrm{m}}^{\mathrm{u}} \mathrm{V}_{\mathrm{b}}}{\mathrm{X}_{2}} \sin \left(\theta_{\mathrm{m}}^{\mathrm{u}}\right)
\end{aligned}
$$

After some mathematical manipulation of Eq. 20, the voltage angle $\theta_{\mathrm{m}}^{\mathrm{u}}$ of bus $\mathrm{m}$ can be expressed as:

$\theta_{\mathrm{m}}^{\mathrm{u}}=\tan ^{-1}\left[\frac{\mathrm{X}_{2} \mathrm{E}^{\prime} \sin (\delta)+\mathrm{X}_{1} \mathrm{~V}_{\mathrm{b}} \mathrm{a} \sin (\alpha)}{\mathrm{X}_{2} \mathrm{E}^{\prime} \cos (\delta)-\mathrm{X}_{1} \mathrm{~V}_{\mathrm{b}} \mathrm{a} \cos (\alpha)+\mathrm{X}_{1} \mathrm{~V}_{\mathrm{b}}}\right]$

Similarly, the reactive power balance equation at bus $\mathrm{m}$ of Fig. 4c is:

$$
\begin{aligned}
Q_{R 1} & =Q_{m i}+Q_{S 2} \frac{\left(V_{m}^{u}\right)^{2}}{X_{1}}-\frac{V_{m}^{u} E^{\prime}}{X_{1}} \cos \left(\theta_{m}^{u}-\delta\right) \\
& =-I_{q} V_{m}^{u}-a b\left(V_{m}^{u}\right)^{2} \cos (\alpha)+\frac{\left(V_{m}^{u}\right)^{2}}{X_{2}}-\frac{V_{m}^{u} V_{b}}{X_{2}} \cos \left(\theta_{m}^{u}\right)
\end{aligned}
$$

From Eq. 22, the voltage magnitude $\mathrm{V}_{\mathrm{m}}^{\mathrm{u}}$ of bus $\mathrm{m}$ can be found as:

$$
V_{m}^{u}=\frac{X_{2} E^{\prime} \cos \left(\delta-\theta_{m}^{u}\right)+X_{1} V_{b} \cos \left(\theta_{m}^{u}\right)+X_{1} X_{2} I_{q}}{X_{1}+X_{2}-X_{1} a \cos (\alpha)}
$$

It can be seen from Eq. 21 and 23 that the voltage magnitude angle at bus $\mathrm{m}$ can be controlled by UPFC control parameters $\left(\mathrm{a}, \alpha\right.$ and $\mathrm{I}_{\mathrm{q}}$ ). Thus in the presence of a UPFC, bus $m$ of the system can be viewed as the terminal of a dependent voltage source whose magnitude and angle depend on the UPFC control parameters ( $\mathrm{a}, \alpha$ and $\mathrm{I}_{\mathrm{q}}$ ).

The electrical output power $\left(\mathrm{P}_{\mathrm{e}}^{\mathrm{u}}\right)$ of the machine can be written as:

$\mathrm{P}_{\mathrm{e}}^{\mathrm{u}}=\frac{\mathrm{E}^{\prime} \mathrm{V}_{\mathrm{m}}^{\mathrm{u}}}{\mathrm{X}_{1}} \sin \left(\delta-\theta_{\mathrm{m}}^{\mathrm{u}}\right)$

The dynamic equations of a simple system with a UPFC can be represented by:

$\dot{\delta}=\omega$

$\dot{\omega}=\frac{1}{\mathrm{M}}\left(\mathrm{P}_{\mathrm{m}}-\mathrm{P}_{\mathrm{e}}^{\mathrm{u}}\right)$

Here $\delta, \omega, \mathrm{M}$ and $\mathrm{P}_{\mathrm{m}}$ are machine angle, speed, moment of output electrical power, respectively, of the machine. The Eq. 26 clearly indicates that the $\mathrm{P}_{\mathrm{e}}^{\mathrm{u}}$ of the machine is main the main factor that dictates the dynamic behavior of machine because both $\mathrm{P}_{\mathrm{m}}$ and $\mathrm{H}$ are usually considered as constant.

Control strategy: This study uses the machine speed control parameters on a UPFC. When the speed deviation is positive $(\omega>0)$, the $\mathrm{P}_{\mathrm{e}}^{\mathrm{u}}$ is raised by controlling parameters on a UPFC; When the speed deviation is negative $(\omega<0)$, the $\mathrm{P}_{\mathrm{e}}^{\mathrm{u}}$ is raised by controlling parameters on a UPFC.

\section{RESULTS}

The presented mathematical model and control strategy is used to study the effect of UPFC on transient stability enhancement of the system of Fig. 2a. In all cases, it is considered that a three phase self clearing fault appears at bus $\mathrm{m}$ and the fault is cleared without changing the network configuration. Figure 5 shows the machine angle curve of the system without and with a UPFC for clearing time $\left(\mathrm{t}_{\mathrm{cl}}\right)=150 \mathrm{msec}$. 


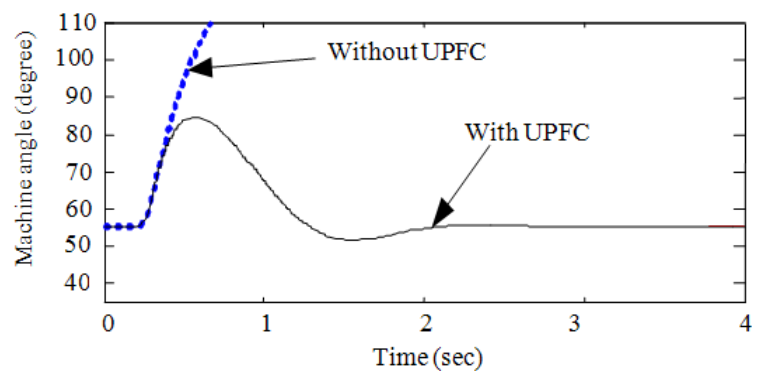

Fig. 5: Machine angle of the system without and with an TCPST for $\mathrm{t}_{\mathrm{cl}}=150 \mathrm{msec}$

\section{DISCUSSION}

It can be observed from the simulation results that the machine angle of the system without a UPFC increases significantly and thus the system is considered as unstable. However, with a UPFC, the system is considered as stable. The maximum value of swing curve is 85.45 degree and the system return to equilibrium point in about $2 \mathrm{msec}$.

\section{CONCLUSION}

This study investigates the capability of the Unified Power Flow Controller (UPFC) on transient stability enhancement of the system. The mathematical model is systematically derived. The presented mathematical model has shown that power flow and stability of system can be regulated by UPFC. This study uses machine speed to control parameters on UPFC. The speed deviation is the main factor to decrease and increase power flow of the system. The simulation results are tested on Single Machine Infinite Bus (SMIB) system. From the simulation results, it indicates that a UPFC can enhance transient stability of the system.

\section{REFERENCES}

Ahmad and N. Al-Husban, 2009. An eigenstructure assignment for a static synchronous compensator. Am. J. Eng. Applied Sci., 2: 812-816. http://www.scipub.org/fulltext/ajeas/ajeas114552.pdf

Augusto, L., P. Fernandes and A. Rocco, 2008. Electric power system under-voltage load shedding protection can become a trap. Am. J. Applied Sci., 6:

1526-1530. http://www.scipub.org/fulltext/ajas/ajas681526530.pdf
Hannan, M.A., A. Mohamed, A. Hussian and M.A. Dabbay, 2009. Development of the unified seriesshunt compensator for power quality mitigation. Am. J. Applied Sci., 6: 978-986. http://www.scipub.org/fulltext/ajas/ajas65978986.pdf

Kumkratug, P., 2010. Fast decoupled power flow for power system with high voltage direct current transmission system. Am. J. Applied Sci., 7: 1115-1117. http://www.scipub.org/fulltext/ajas/ajas7811151117.pdf

Moghadasi, S., A. Kazemi, M. Fotuhi-Firuzabad and A. Edris, 2008. Composite system reliability assessment incorporating an interline power flow controller. IEEE Trans. Power Deliv., 2: 1191-1199. DOI: 10.1109/TPWRD.2008.915821 http://ieeexplore.ieee.org/stamp/stamp.jsp?tp=\&arn umber $=4476472$

Pizano-Matinez, A., C.R., Fuerte-Esquivel and D., Ruiz-Vega, 2009. Global transient stability contrained optimal power flow using an OME method. IEEE Trans. Power Syst., 25: 392-403. DOI: 10.1109/TPWRS.2009.2036494

http://ieeexplore.ieee.org/stamp/stamp.jsp?tp=\&arn umber $=5357533$

Jiang, X., X. Fang, J.H. Chow, A. Edris and E. Uzunovic et al., 2008. A novel approach for modeling voltage sourced converter based FACTS controllers. IEEE Trans. Power Deliv., 4: 25912598. DOI: 10.1109/TPWRD.2008.923535 http://ieeexplore.ieee.org/stamp/stamp.jsp?tp=\&arn umber $=4518922$

Zarate-Minano, R., T. Van Cutsem, F., Milano, A.J. Conejo, 2010. Securing transient stability using time domain simulations within an optimal power flow. IEEE Trans. Power Syst., 5: 243-253. DOI: 10.1109/TPWRS.2009.2030369 